For table of contents use only

\title{
Mechanistic Investigation of the Electrochemical Reduction of $\mathrm{Cp}_{2} \mathrm{TiX}_{2}$
}

Rasmus Juel Enemærke, Jens Larsen, Troels Skrydstrup and Kim Daasbjerg*

\section{Summary:}

Electrochemical reduction of $\mathrm{Cp}_{2} \mathrm{TiX}_{2}$ leads mainly to the formation of $\mathrm{Cp}_{2} \mathrm{TiX}_{2}^{-}$for $\mathrm{X}=\mathrm{Cl}$, whereas a mixture of $\mathrm{Cp}_{2} \mathrm{TiX}$ and $\left(\mathrm{Cp}_{2} \mathrm{TiX}\right)_{2}$ is generated for $\mathrm{X}=\mathrm{Br}$ and $\mathrm{I}$. The latter species are found to be the most reactive ones, although they should be poorer electron donors according to the standard potentials determined. 


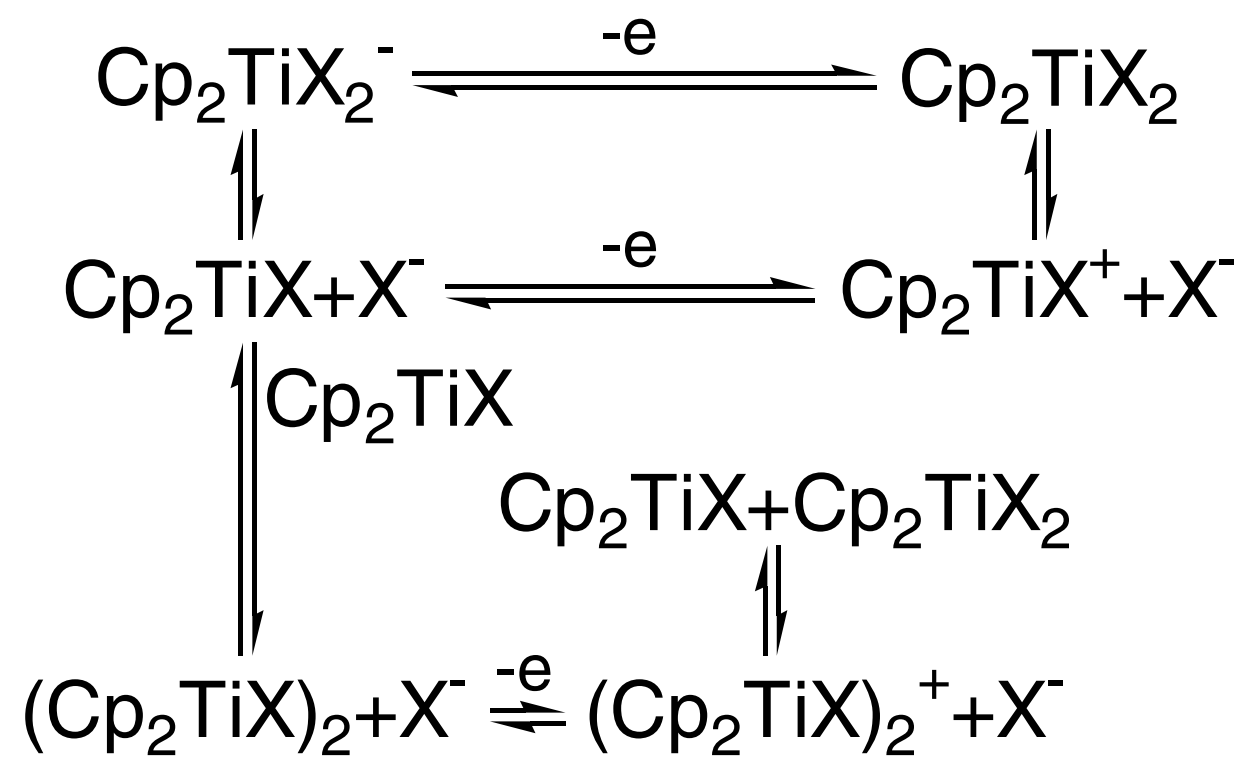

